\title{
Nanog down-regulates the Wnt signaling pathway via $\beta$-catenin phosphorylation during epidermal stem cell proliferation and differentiation
}

\author{
Peng Cheng ${ }^{1+}$, Xuying Sun ${ }^{1,2+}$, Delong Yin ${ }^{3}$, Fei Xu' ${ }^{1}$, Kaixiang Yang ${ }^{1}$, Liang Qin ${ }^{1}$, Yonghui Dong ${ }^{1}$, Fengjing Guo ${ }^{1}$, \\ Anmin Chen ${ }^{1}$, Weikai Zhang ${ }^{1 *}$ and Hui Huang ${ }^{1 *}$
}

\begin{abstract}
Background: Skin tissue homeostasis is maintained by a balance between the proliferation and differentiation of epidermal stem cells (EpSCs). EpSC proliferation and differentiation are complex processes regulated by many factors and signaling pathways. This study aimed to explore the connection between the Nanog and the Wnt/ $\beta$ catenin pathway in the proliferation and differentiation of EpSCs.

Results: Our results demonstrated that during the study period, EpSC underwent differentiation when incubated in the presence neuropeptide substance P (SP), there was an opposing expression trend of Nanog and $\beta$-catenin after SP treatment, which could be antagonized by the Wnt antagonist, Dkk-1. The transduced EpSCs had a greater proliferative ability than the SP treatment group and they did not undergo differentiation upon SP treatment. More important, $\beta$-catenin expression was down-regulated but phosphorylated $\beta$-catenin expression and phosphorylated GSK-3ß expression was up-regulated upon Nanog overexpression.

Conclusions: These results strongly suggest that Nanog plays an important role in maintaining the proliferation and differentiation homeostasis of EpSCs by promoting $\beta$-catenin phosphorylation via GSK-3 $\beta$ to inhibit the activity of the $\mathrm{Wnt} / \beta$-catenin signaling pathway. This is important for precise regulation of proliferation and differentiation of EpSC in the application of tissue engineering.
\end{abstract}

Keywords: Nanog, Wnt/ß-catenin, Epidermal stem cells, Proliferation, Differentiation

\section{Background}

Skin is the largest organ of the human body; it plays a key role in protecting the body against pathogens. The homeostasis of skin tissue is maintained by rare but pluripotent epidermal stem cells (EpSCs) and their progeny, transient amplifying (TA) cells [1,2]. As pluripotent cells, EpSCs not only have an unlimited self-renewal capability to maintain a certain population but they also differentiate to form structures such as hair follicles and sebaceous glands $[2,3]$.

\footnotetext{
*Correspondence: wk-zhang@hotmail.com; 2007hh@gmail.com

${ }^{\dagger}$ Equal contributors

${ }^{1}$ Department of Orthopedics, Tongji Hospital, Tongji Medical College, Huazhong University of Science and Technology, Wuhan 430030, P.R. China Full list of author information is available at the end of the article
}

Transcription factors and signals determine whether EpSCs undergo self-renewal or differentiation. Several studies have established the central role of Nanog in maintaining pluripotency and preventing differentiation [4-7]. Nanog simultaneously increases the expression of genes conferring pluripotency and decreases the expression of genes driving cell differentiation. Increasing evidence also supports the involvement of the $\mathrm{Wnt} / \beta$ catenin signaling pathway in the self-renewal and differentiation of EpSCs [8-10]. $\beta$-catenin is of central importance in the $\mathrm{Wnt} / \beta$-catenin signaling pathway. Numerous articles have also reported that the fate of EpSC is controlled by an intricate relationship between different signaling pathways and transcription factors, especially Nanog and the $\mathrm{Wnt} / \beta$-catenin signaling 
pathway [11-14]. However, previous research has not been able to clearly reveal the underlying molecular mechanism of EpSC proliferation and differentiation. Thus, the relationship between Nanog and the Wnt/ $\beta$-catenin signaling pathway in EpSC proliferation and differentiation is of great interest.

In this study, we evaluated the relationship between the Wnt/ $\beta$-catenin signaling pathway and Nanog in the proliferation and differentiation of EpSCs. Rat EpSCs were infected with lentivirus overexpressing Nanog. SP,a neuropeptide present in primary sensory neurons, belongs to the tachykinin family and can activate $\mathrm{Wnt} / \beta$-catenin signaling pathway [15]. Transduced or untransduced cells were subsequently incubated in the presence or absence of SP. The effect of Nanog and SP on EpSC proliferation was tested in vitro. Subsequently, the expression of $\beta$-catenin and Nanog were evaluated in SP treated EpSCs using western blotting and PCR. In addition, the effect of Nanog on $\beta$-catenin expression was investigated in EpSCs using a lentivirus infection and/or SP treatment.

\section{Results}

\section{Characterization of EpSCs}

Rat EpSCs were isolated using rapid substrate attachment. Collagen type IV was used in this study to isolate EpSCs because collagen type IV is the ligand of $\beta 1$ integrin, which is a potent cell marker of EpSCs. The rapidly adherent cells demonstrated stem cell characteristics as bird nest-like or slabstone-like (Figure 1A), which is the typical morphology of EpSCs. The expression of CD34 and $\beta 1$ integrin was examined by immunofluorescence. Both CD34 (Figure 1B) and $\beta 1$ integrin (Figure 1C) were highly expressed in the isolated cells, which proved that these isolated population were the EpSCs [16,17]. On the other hand, EpSC differentiation was detected after 12 days of $10^{-7}$ M SP treatment or Wnt agonist treatment. Differentiated EpSCs showed the special morphologies as long spindle or polygonal (Figure 1D). Furthermore, differentiated EpSCs expressed CK18, which are expressed in the epithelial cells [18], as demonstrated by immunocytochemistry (Figures 1E, 1F). However, Wnt antagonist Dkk-
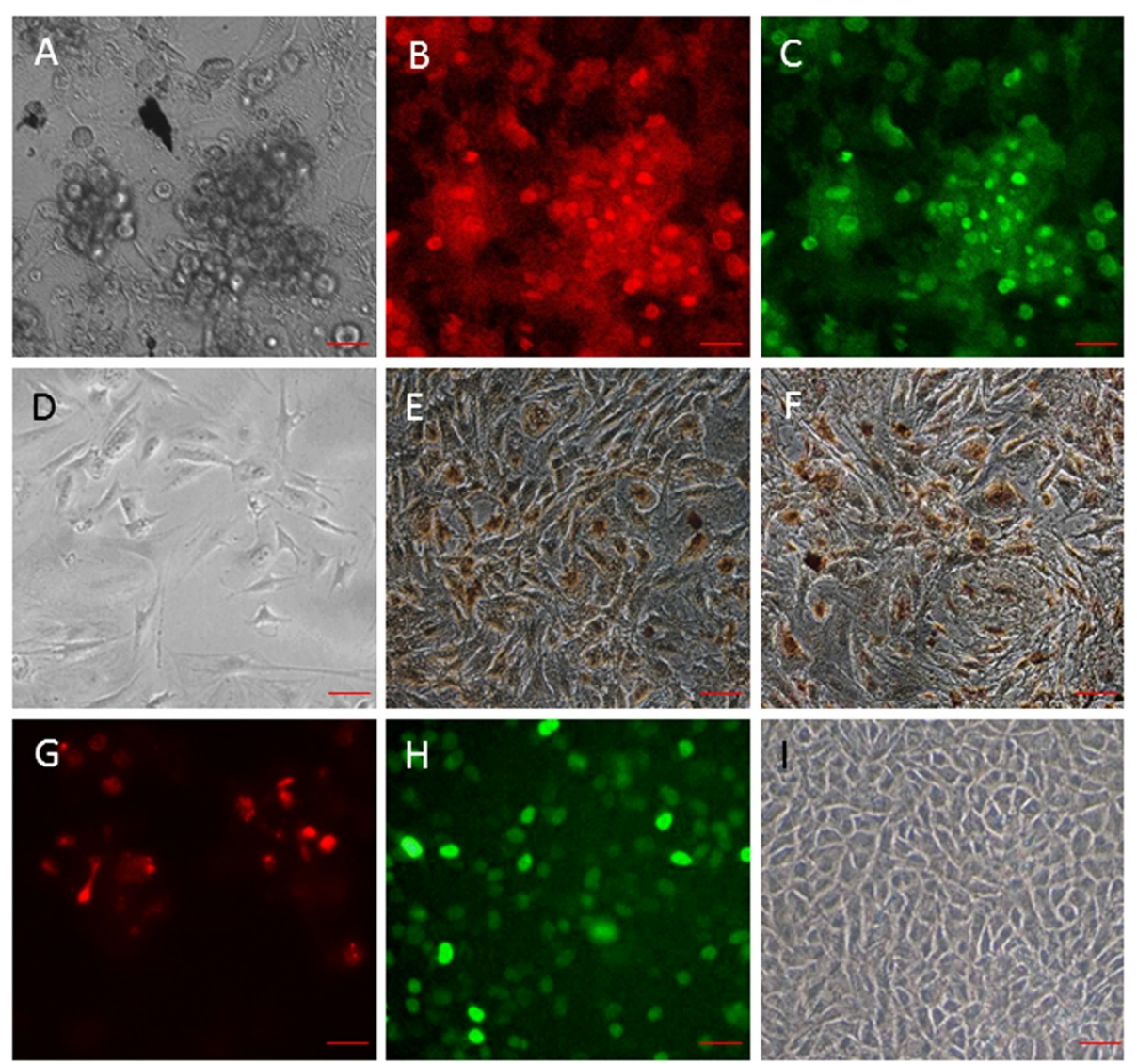

Figure 1 Characterization of the isolated EpSCs. The morphology of the isolated cells are bird nest-like or slabstone-like (A). The isolated cells positively express CD34 (B) and $\beta 1$ integrin (C) as detected by immunofluorescence. (D) EpSCs treated with $10^{-7} \mathrm{M}$ for 12 days showed polygonal or long spindle morphology. (E) CK18 expression in these SP-induced EpSCs indicated these cells were differentiated, as demonstrated by immunocytochemistry. (F) Wnt agonist triggers EpSC differentiation, as demonstrated by CK18 immunocytochemistry. (G) CD34 positive expression in the SP with Dkk-1 treated EpSCs demonstrated that these cells were still stem cells, as detected by immunofluorescence. $\mathbf{( H )}$ Fluorescence microscopy image of the transduced EpSCs. (I) The transduced EpSCs did not undergo differentiation upon SP treatment. Scale bar $=20 \mu \mathrm{m}$. 
1 can antagonize SP induced EpSC differentiation. CD34 positive expression in the SP with Dkk-1 treated EpSCs (Figure 1G) indicated that these cells were not differentiated. After infection with lentivirus-Nanog, EpSCs produced green fluorescence under a fluorescent microscope (Figure $1 \mathrm{H}$ ). The transduced EpSCs did not undergo differentiation during the study period (Figure 1I).

\section{Proliferative ability of EpSCs infected with lentivirus or treated with SP in vitro}

$\mathrm{A}_{450}$, which represents EpSC proliferative ability, was tested at one-day intervals from day 2 to day 12 using a CCK-8 kit. A strong linear increase in $\mathrm{A}_{450}$ between day 2 and day 12 was observed, indicating EpSC proliferation. The proliferative ability of EpSCs infected with control lentivirus vector was similar to the control, which had no significant difference at any time point. However, the proliferative ability of transduced EpSCs was much greater than the SP treatment group, control lentivirus vector infected group, and control during the study period. In addition, EpSCs treated with SP proliferated faster than the control in the first 10 days; on day 12 , the proliferative rate of SP treated group reached a plateau while the control continued to rapidly proliferate (Figure 2) $(\mathrm{P}<0.05)$.

\section{The expression of Nanog and $\beta$-catenin in EpSCs treated with SP}

To reveal change in expression of Nanog and $\beta$-catenin in the EpSC differentiation process induced by $10^{-7} \mathrm{M}$ SP, we detected Nanog and $\beta$-catenin expression at the mRNA and protein level every three days from day 0 to day 12. q-PCR analysis revealed that Nanog expression decreased. Nanog expression was significantly lower from days $3-12$ than at day $0(\mathrm{P}<0.05)$. However, $\beta$ catenin expression increased significantly from days $3-$ 12 compared to day $0(\mathrm{P}<0.05)$ (Figure $3 \mathrm{~A})$. Western

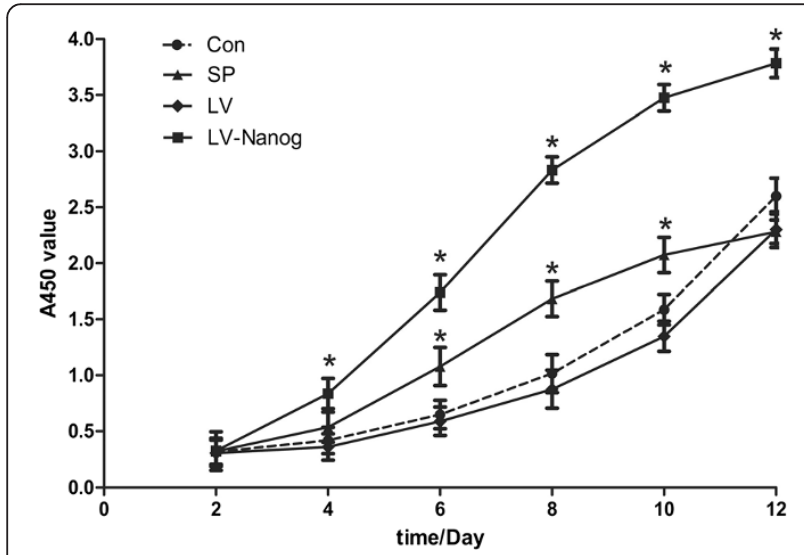

Figure 2 Proliferative ability of EpSCs in vitro, as measured by the CCK-8 assay. blot results were similar to q-PCR results (Figures 3B, 3C, 3D).

To confirm that the expression of Nanog and $\beta$ catenin in the EpSC differentiation process induced by $10^{-7} \mathrm{M} \mathrm{SP}$ was related to $\mathrm{Wnt} / \beta$-catenin signaling pathway, we used a specific Wnt antagonist, Dkk-1, and then detected Nanog and $\beta$-catenin expression at the mRNA and protein level every three days from day 0 to day 12 . q-PCR analysis revealed that at any time on or after day $3 \beta$-catenin expression was lower and Nanog expression was higher in both SP and Dkk-1treatment group than SP treatment group $(\mathrm{P}<0.05)$ (Figure $4 \mathrm{~A}$ and $4 \mathrm{~B}$ ). At day 12 , protein of Nanog and $\beta$-catenin were also detected. The western blotting results were in accordance with qPCR results. $(P<0.05)$ (Figures $4 \mathrm{C}, 4 \mathrm{D}$ and $4 \mathrm{E})$.

\section{The expression of Nanog and $\beta$-catenin in EpSCs infected} with lentivirus

To reveal the effect of Nanog overexpression on $\beta$ catenin and confirm the lentivirus itself do not affect the expression of Nanog or $\beta$-catenin, we infected EpSCs with lentivirus loaded with or without Nanog. Nanog and $\beta$-catenin expression at mRNA were detected at different time point (day 1- day 12) (Figures 5A and 5B). The results of q-PCR revealed that Nanog expression in the lentivirus-Nanog group increased remarkably at day 3 , and continuely increased every day. However, $\beta$ catenin expression decreased from day 3 , which were quite opposite to the Nanog expression. At day 12, protein of Nanog and $\beta$-catenin were also detected (Figures $5 \mathrm{C}$, $5 \mathrm{D}$ and $5 \mathrm{E})$. Western blot results were similar to $\mathrm{q}-\mathrm{PCR}$ results. Besides, there were significant differences between the transduced group and control both at mRNA and protein level. And more, there was no significant difference between the control lentivirus vector infected group and control at either mRNA or protein level (Figure 5) $(\mathrm{p}<0.05)$.

\section{Negative feedback of Nanog on the Wnt / $\beta$-catenin signaling pathway}

To explore how Nanog affects the Wnt/ $\beta$-catenin signaling pathway, EpSCs infected with lentivirus encoding Nanog were incubated in the presence or absence of SP. Nanog, $\beta$-catenin and c-myc in Wnt $/ \beta$-catenin signaling pathway were detected both at mRNA and protein level. At the mRNA level, Nanog expression in transduced cells in the absence or presence of SP was significantly higher than the control or SP-only treatment groups (Figure 6A) $(\mathrm{P}<0.05)$. In contrast to Nanog expression, pt]?> $\beta$-catenin expression in transduced cells in the absence or presence of SP was significantly lower than the control or SPonly treatment groups (Figure 6B) $(\mathrm{P}<0.05)$. C-myc, a downstream gene in the $\mathrm{Wnt} / \beta$-catenin signaling pathway, trended with $\beta$-catenin expression (Figure $6 \mathrm{C}$ ). The western blotting 

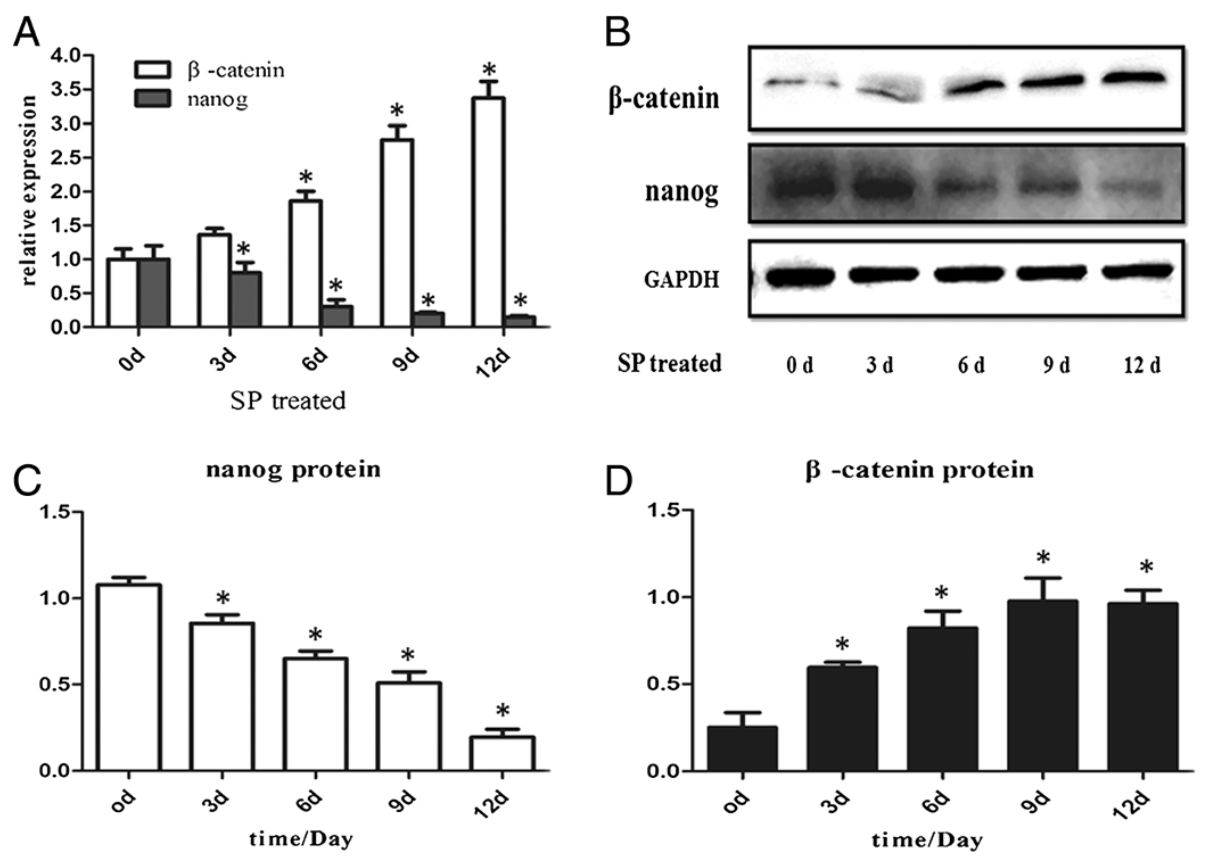

Figure 3 Expression of $\beta$-catenin and Nanog in EpSCs treated with SP. $\beta$-catenin and Nanog were measured at different time points (day 0-day 12) at the mRNA (q-PCR) and protein (western blot) level (A and B). The bands of each protein were quantitatively analyzed (C and D) Both q-PCR and western blot analysis showed that $\beta$-catenin expression was significantly higher on or after day 3 than at day 0 . Nanog and $\beta$-catenin expression had an inverse relationship ( $\left.{ }^{*} P<0.05\right)$.
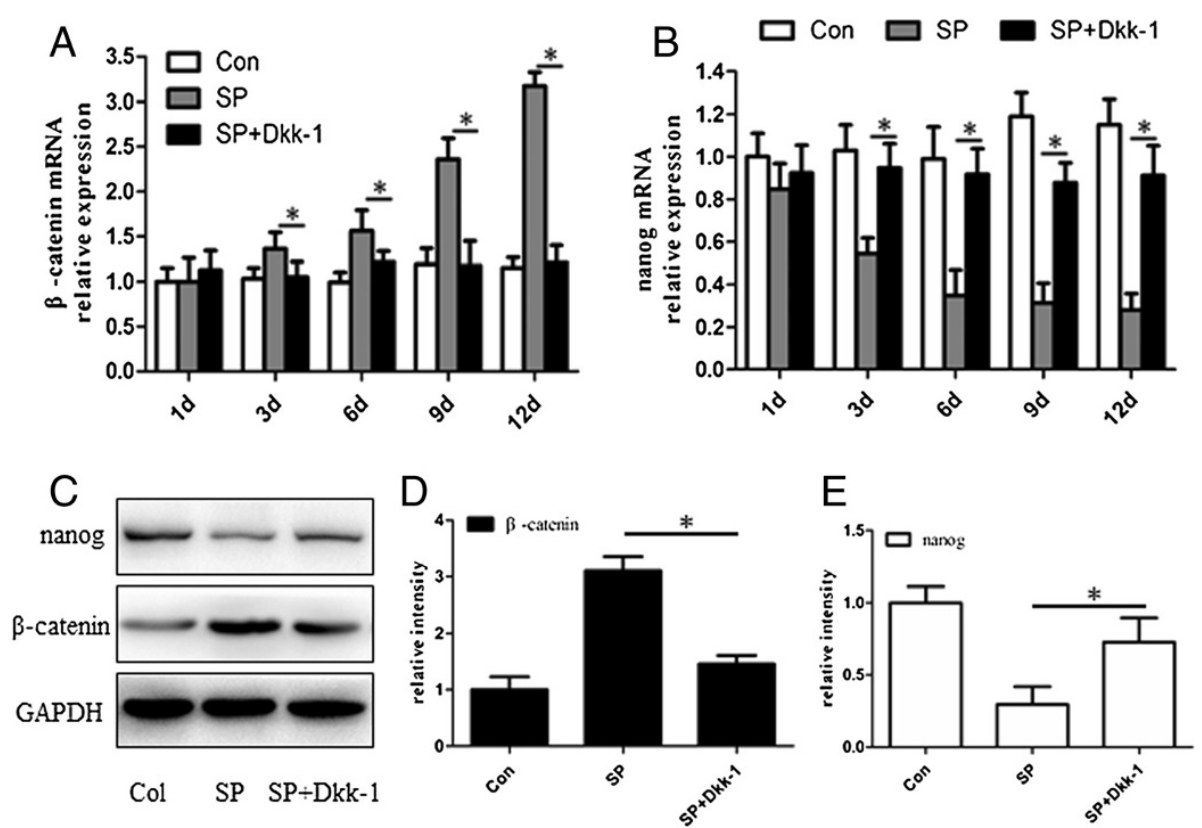

Figure 4 Expression of $\beta$-catenin and Nanog in EpSCs treated with Wnt antagonist, Dkk-1. Real-time PCR analysis of $\beta$-catenin mRNA (A) and Nanog mRNA (B) were obtained at different time points (day 1- day 12) in the control, SP treated group and SP with Dkk-1 treated group. The result showed that there were significant differences between the SP group and SP with Dkk-1 group on or after day $3\left({ }^{*} P<0.05\right)$. At day 12 , protein of Nanog and $\beta$-catenin were also detected (C). The bands of both proteins in each group were analyzed quantitatively (D and E). Werstern blot results were similar to q-PCR results (Con: control; SP: SP treated group; SP + Dkk-1: SP with Dkk-1 treated group). 

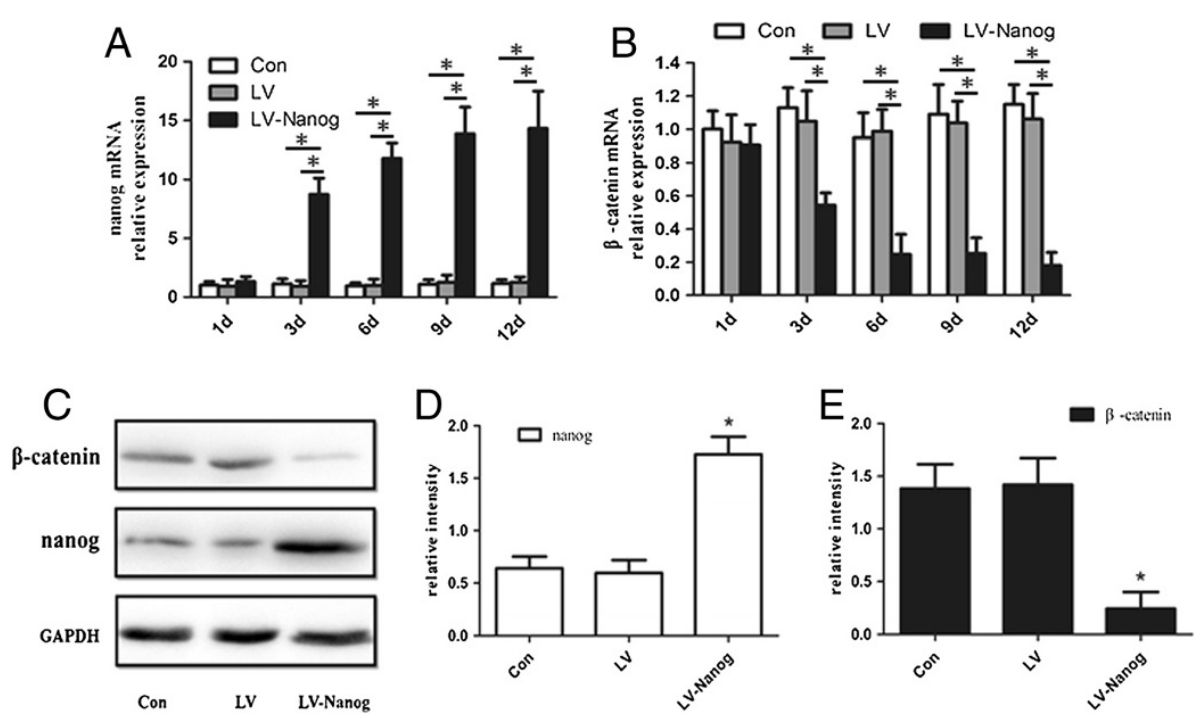

Figure 5 Expression of $\beta$-catenin and Nanog in EpSCs infected with lentivirus. Real-time PCR analysis of Nanog mRNA (A) and $\beta$-catenin mRNA (B) were obtained at different time points (day 1- day 12) in the control, control lentivirus vector infected group and transduced group. The results showed that there were no significant differences between the control and control lentivirus vector infected group. However, significant differences existed in the transduced group with the control on or after day $3\left({ }^{*} \mathrm{P}<0.05\right)$. At day 12 , protein of Nanog and $\beta$-catenin were also detected (C). The bands of both proteins in each group were analyzed quantitatively ( $D$ and E). Western blot results were similar to q-PCR results (Con: control; LV: control lentivirus vector infected group; LV-Nanog: transduced group).

results were in accordance with q-PCR data. (Figures 5D, 5E, and $6 \mathrm{~F})$.

To demonstrate the change in $\beta$-catenin expression in detail, total $\beta$-catenin,phosphorylated $\beta$-catenin, total GSK-3 $\beta$ protein and phosphorylated GSK-3 $\beta$ protein were also measured using western blotting (Figure 7A). Figure $7 \mathrm{C}$ shows that total $\beta$-catenin protein expression was significantly higher in the control and SP treated groups compared with transduced group in the absence or presence of SP $(\mathrm{P}<0.05)$. However, phosphorylated $\beta$ catenin expression in EpSCs, which is inactivated $\beta$ catenin, was significantly different compared with total $\beta$-catenin protein expression $(\mathrm{P}<0.05)$ (Figure $7 \mathrm{D})$. Phosphorylated $\beta$-catenin protein expression in the control and SP treated groups was significantly lower than transduced cells in the absence or presence of SP. This result is the opposite of the results obtained with total $\beta$-catenin protein expression. Further analysis could be obtained, the ratio of phosphorylated $\beta$-catenin to total $\beta$-catenin was significantly high in transduced EpSCs (Figure $7 \mathrm{E})(\mathrm{P}<0.05)$. In addition, the ratio of phosphorylated GSK-3 $\beta$ to total GSK-3 $\beta$ was another indicator of inactivated $\beta$-catenin. With the intensity quantitative analysis, it had a similar trendency with the ratio of phosphorylated $\beta$-catenin to total $\beta$-catenin (Figure 7B) $(\mathrm{P}<0.05)$.

\section{Discussion}

As the primary barrier in the human body, skin protects humans from infection, radiation and wounds. However, skin, especially the epidermis, may be injured by external insults. The proliferation and differentiation of EpSCs and their progeny of TA cells greatly affect skin repair $[2,19,20]$. This process is controlled by an intricate relationship between different signaling pathways and transcription factors, especially the Wnt/ $\beta$-catenin signaling pathway and Nanog [21-23].

Nanog is a pluripotent state-specific transcription factor that plays a critical role in regulating cell fate during embryonic development, maintaining pluripotent epiblasts and preventing differentiation [24,25]. Nanog is also proposed as a transcription repressor that inhibits important genes for cell differentiation $[7,26]$. Our results showed that the proliferation ability of transduced EpSCs is much greater than the control and SP treated groups (Figure 2). Additionally, transduced EpSCs treated with SP did not undergo differentiation (Figure 1I). These results using EpSCs agree with previous reports that Nanog can promote proliferation and inhibit differentiation of stem cells. On the other hand, accumulating evidence indicates that the $\mathrm{Wnt} / \beta$-catenin signaling pathway plays a critical role in the lineage decision/commitment process $[10,23,27,28]$. In contrast, there are also some reports that the $\mathrm{Wnt} / \beta$-catenin signaling pathway plays a pivotal role in the maintenance of pluripotency as well as in the process of somatic cell reprogramming [9,29-31]. These dramatically different observations upon activation of the Wnt signaling cascade have fueled enormous controversy concerning the role of Wnt signaling in the maintenance of 


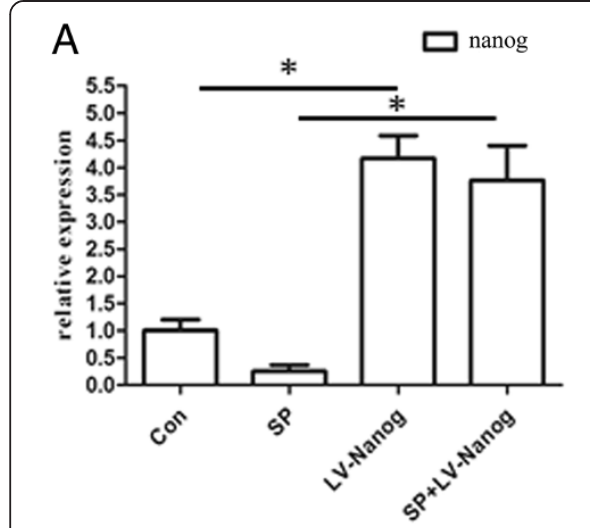

D

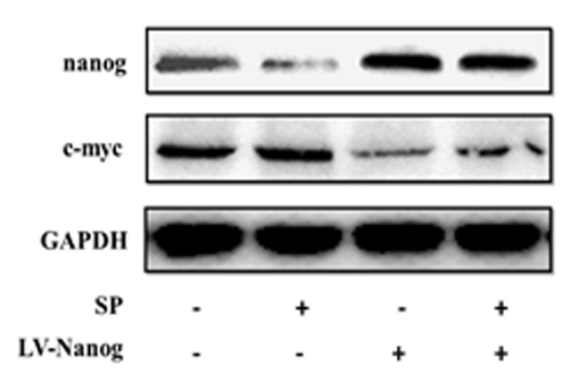

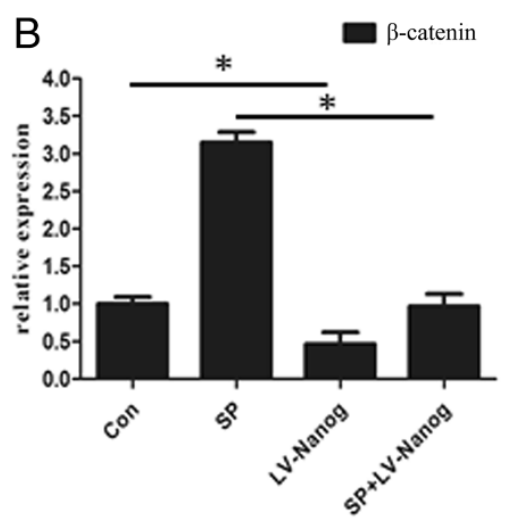

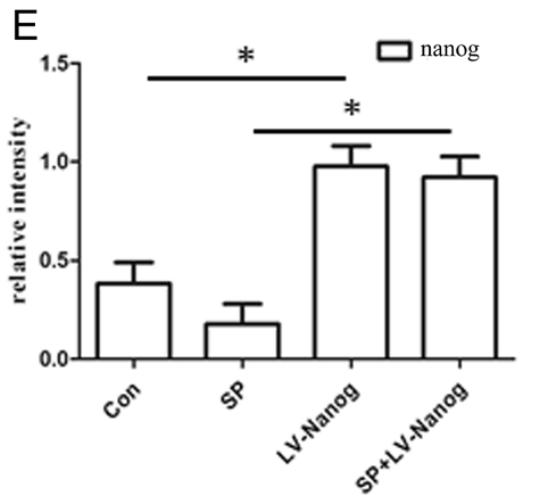

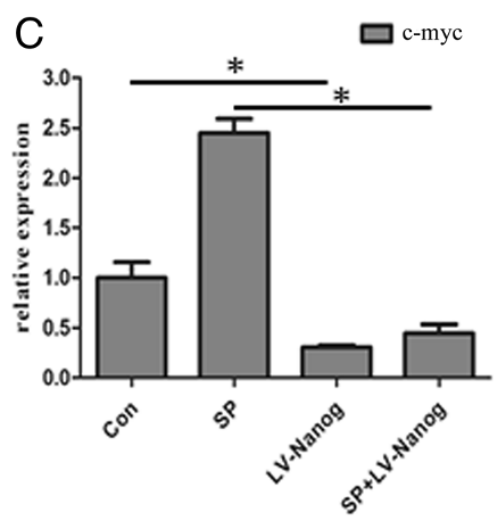

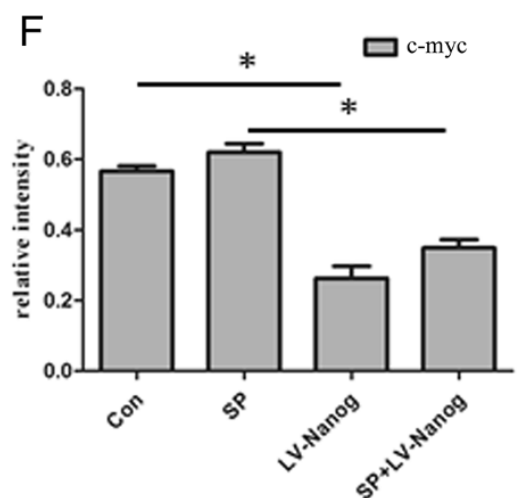

Figure 6 Overexpression of Nanog inhibits the Wnt signaling pathway. Real-time PCR analysis of gene expression ((A) Nanog, (B) $\beta$-catenin, and (C) c-myc) of the EpSCs in the control, SP-treated group, transduced group, and the combination treatment group. At the protein level, Nanog, c-myc, and total $\beta$-catenin were also detected (D). The bands of Nanog and c-myc protein in each group were analyzed quantitatively (E and F). ( ${ }^{*}$ < $\left.<0.05\right)$ (Con: control; SP: substance P treated group; LV-Nanog: transduced group).

differentiation potency and the induction of stem cells. Our results in EpSCs support the former conclusion. In this study, EpSCs were differentiated when they were treated with a Wnt agonist (Figure 1F) and the differentiation was antagonized by Dkk-1(Figure 1G). This result supports evidence that the $\mathrm{Wnt} / \beta$-catenin signal pathway affects EpSCs differentiation.

It is noteworthy that treatment with $10^{-7} \mathrm{M}$ SP caused a rapid proliferation of EpSCs into TA cells in the first twelve days, which subsequently had a limited proliferative ability (Figure 2). This result agrees with our previous study regarding the effect of SP on EpSCs [32]. Previous reports also support our findings [33,34]. From day 12, the EpSCs underwent differentiation, manifesting the typical morphology and expressing CK18, which is an EpSCs differential marker [35,36] (Figures 1D, 1E). This is a new observation compared to our previous research. In this process, the expression of the pluripotency protein Nanog decreased significantly. However, $\beta$ catenin transcription and translation increased (Figure 3). Besides, the increase of $\beta$-catenin could be counteracted by Dkk-1 (Figure 4). The opposing expression trends of
Nanog and $\beta$-catenin suggested that there should be an interaction between them (Figures 3 and 4).

To prove this hypothesis, we infected lentivirus-Nanog into EpSCs in vitro (Figure 1H). CCK-8 results revealed that the transduced EpSCs had a strong proliferative ability, while the control lentivirus vector infection showed no effect on the EpSCs proliferative ability (Figure 2). Besides, the control lentivirus vector infection also did not interfere with Nanog and $\beta$-catenin expression either (Figure 5). Nanog counteracted SP-induced cell differentiation (Figures 1I and 6A). The most important result is that $\beta$-catenin expression in the transduced EpSCs was notably decreased as measured by q-PCR and western blot (Figure 6). This result suggests that Nanog can inhibit EpSC differentiation by inhibiting $\beta$-catenin expression. $\mathrm{C}$-myc, a downstream target of $\mathrm{Wnt} / \beta$-catenin signaling pathway, binds to promoter sequences after activation by $\beta$-catenin-TCF complexes. Haegele et al. found that the activation of c-myc and its downstream targets Cyclin-dependent kinase 2 (CDK) and Cyclin A could up-regulate BMPs and cause embryonic stem cell differentiation [31]. In the SP-treated groups, c-myc 


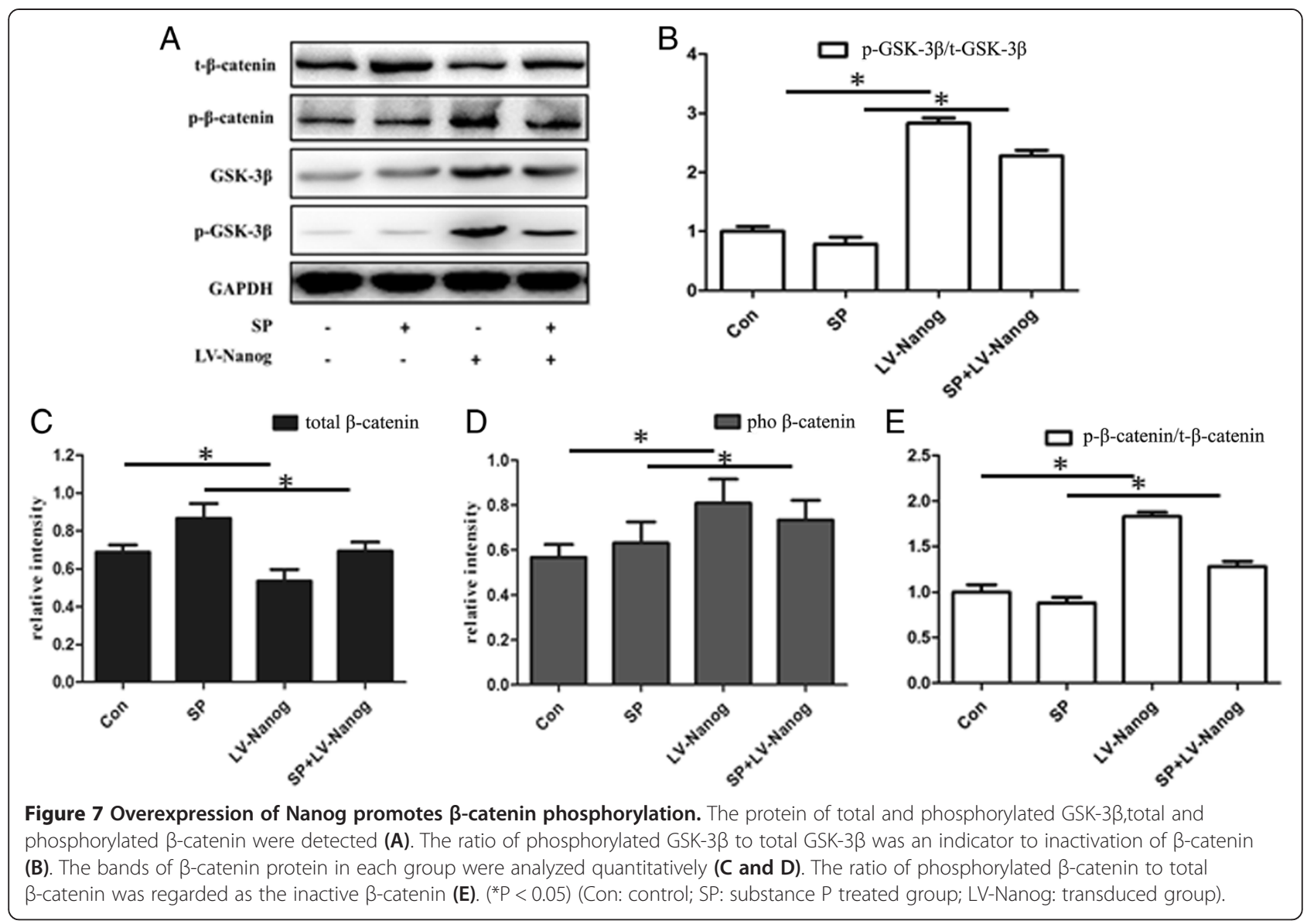

expression of the transduced EpSCs was also suppressed both at mRNA and protein level (Figures 6C, $6 \mathrm{~F})$. The change in $\mathrm{c}$-myc expression agreed with $\beta$ catenin changes in the transduced EpSCs, which indirectly demonstrates that $\beta$-catenin is involved in EpSC differentiation. This result further proved that Nanog can maintain EpSC pluripotency and prevent differentiation by inhibiting the $\beta$-catenin expression.

To explore the potential mechanism of this process, we measured the levels of phosphorylated $\beta$-catenin protein, phosphorylated GSK-3 $\beta$ and total GSK-3 $\beta$ in each group. It is well known that the activity of the $\mathrm{Wnt} / \beta$-catenin signaling pathway is affected by glycogen synthase kinase (GSK). GSK-3 $\beta$ is phosphorylated and results in $\beta$-catenin phosphorylation and its subsequent degradation by the ubiquitin-mediated pathway [29,37]. In this experiment, we found that the ratio of phosphorylated $\beta$-catenin to total $\beta$-catenin paralleled Nanog expression in each group (Figure 7E), which is in common with the ratio of phosphorylated GSK-3 $\beta$ to total GSK-3 $\beta$ (Figure 7B). Therefore, we conclude that Nanog inhibits $\beta$-catenin activity through the phosphorylation of $\beta$-catenin via GSK-3 $\beta$. Thus, we can infer the underlying process by which EpSCs execute their function. When skin is not injured, Nanog maintains the multi-potential and proliferative state of EpSCs through inhibiting $\beta$-catenin expression via $\beta$ catenin phosphorylation. However, when skin needs to repair an injury, negative feedback from $\beta$-catenin on Nanog suppresses its expression and induces EpSC differentiation. The whole process balances the differentiation and proliferation of EpSCs.

\section{Conclusion}

In summary, our study showed that Nanog and the Wnt/ $\beta$-catenin signaling pathway are involved in the regulation of EpSC proliferation and differentiation, which is necessary to maintain EpSCs homeostasis in the skin. The underlying mechanism is that Nanog inhibits the activity of the Wnt $/ \beta$-catenin signaling pathway via GSK- $3 \beta$ mediated $\beta$-catenin phosphorylation. This finding represents an important step towards understanding the precise regulation of EpSC proliferation and differentiation, which has important applications in tissue engineering.

\section{Materials and methods}

\section{Cell culture}

Sprague-Dawley (SD) male rats were purchased from HUST Laboratory Animal Center (Wuhan, China). The 
Ethics Committee of Tongji Medical College, Huazhong University of Science and Technology, approved all animal care and experimental procedures. The EpSCs isolated procedure was regarded as a standard protocol which was first repoted by Liu Y [16]. Skin tissue was obtained from the back of neonatal SD rats by plastic surgical procedures and was washed in phosphatebuffered solution (PBS). Connective tissue and subcutaneous fat were removed. The skin sample was sterilized with $70 \%$ ethanol for $5 \mathrm{~min}$, rinsed in PBS, and minced into 5-mm wide strips using a sharp scalpel; the strips were treated with $0.25 \%$ Dispase (Roche, Switzerland) solution at $4^{\circ} \mathrm{C}$ overnight. The epidermis was mechanically separated from the dermis and incubated in $0.25 \%$ trypsin solution at $37^{\circ} \mathrm{C}$ for $15 \mathrm{~min}$ to dissociate the cells; enzyme activity was then blocked with Dulbecco's modified Eagle's medium (DMEM; Gibco, USA) containing $10 \%$ fetal bovine serum (FBS; Gibco, USA), and the cells were suspended with a pipette. To remove any remaining tissue pieces, the cell suspension was filtered through a stainless steel mesh attached to a $60-\mathrm{mm}$ cell culture plate. The cells were transferred to a $15-\mathrm{ml}$ centrifuge tube and collected by centrifugation for $5 \mathrm{~min}$ at $250 \mathrm{~g}$. To select stem cells, $1 \times 10^{6}$ dissociated epidermal cells were plated onto collagen type IV (Sigma, USA) $(100 \mu \mathrm{g} / \mathrm{ml})$-coated dishes at room temperature for $15 \mathrm{~min}$. The unattached cells were removed, and the rapidly adherent epidermal cells were cultured with keratinocyte serum-free medium (K-SFM; Gibco, USA) supplemented with epidermal growth factor (EGF) (KSFM; Gibco, USA), bovine pituitary extract (BPE; Gibco, USA), and $0.05 \mathrm{mM}$ calcium chloride $\left(\mathrm{CaCl}_{2}\right.$, Sigma, USA) at $37^{\circ} \mathrm{C}$ under $5 \% \mathrm{CO}_{2}$ in a humidified incubator for two days before replacing the medium. The medium was changed every other day.

\section{Lentivirus vector construction and EpSC infection}

The coding sequence of rat Nanog was PCR amplified from GV208: rat-Nanog using primers with AgeI/AgeI overhangs and was cloned into pTZ58 (Fermentas, Vilnus, Lithuania). The AgeI/Agel fragment was then sub-cloned into pUbi (AgeI/AgeI) and pEGFP-C1 (Clontech, Mountain View, CA) (AgeI/AgeI) to generate Ubi-Nanog-EGFP encoding plasmids, respectively. To produce lentivirus, the pBABE-puro plasmids were co-infected along with the helper plasmids into $293 \mathrm{~T}$ cells, and the medium was harvested $36 \mathrm{~h}$ and $72 \mathrm{~h}$ after infection. EpSC infection was performed by incubating the cells in virus-enriched medium for $12 \mathrm{~h}$, which included $4 \mu \mathrm{g} / \mathrm{ml}$ polybrene. Transduced cells were identified for EGFP expression under a fluorescence microscope. The transduced EpSCs were divided into two groups: the first group of EpSCs was treated with SP for 12 days after infection; the second group of EpSCs was cultured for 12 days. EpSCs were also infected with control lentivirus vector and cultured for 12 days. EpSCs without any treatment were used as control.

\section{Immunofluorescence}

The isolated cells were cultured in a 6-well plate $\left(10^{4}\right.$ cells/well) for $24 \mathrm{~h}$. The cells were rinsed five times with PBS, fixed with $4 \%$ paraformaldehyde solution for $15 \mathrm{~min}$ at room temperature, and permeated with $0.5 \%$ Triton X-100-PBS solution for $5 \mathrm{~min}$. After blocking with 3\% BSA in PBS for $30 \mathrm{~min}$, the cells were respectively incubated with primary antibodies to anti-CD 34 antibody (rabbit polyclonal antibody, 1:50, Santa Cruz Biotechnology, Inc.) and anti- $\beta 1$ integrin antibody (rabbit polyclonal antibody, 1:50, Boster Biological Technology, Ltd.) at $4^{\circ} \mathrm{C}$ overnight. The primary antibody binding was detected via the corresponding goat antirabbit IgG: Cy3 and goat anti-mouse IgG FITC (Boster Biological Technology, Ltd.). Staining was examined under a fluorescence microscope.

\section{Immunocytochemistry}

The isolated cells were cultured in a 6-well plate $\left(10^{4}\right.$ cells/well) for $24 \mathrm{~h}$. The cells were treated with $10^{-7} \mathrm{M}$ $\mathrm{SP}$ or $\mathrm{LiCl}$, a Wnt agonist, to induce differentiation for 12 days. The cells were rinsed five times with PBS, fixed with $4 \%$ paraformaldehyde solution for $15 \mathrm{~min}$ at room temperature, and permeated with $0.5 \%$ Triton X-100PBS solution for $5 \mathrm{~min}$. The cells were incubated with primary antibodies to anti-cytokeratin 18 antibody (CK18) (rabbit polyclonal antibody, 1:50, Santa Cruz Biotechnology, Inc.) at $4^{\circ} \mathrm{C}$ overnight. Subsequent procedures were performed according to the SP-9000 Histostain-Plus Kit instructions (ZSGB-BIO, Beijing, China). The cells were observed under a microscope (Bio-Rad, Hercules, CA, USA).

\section{Cell Counting Kit-8 (CCK-8) assay}

EpSCs were plated in 96-well plates $\left(2 \times 10^{4}\right.$ cells/well $)$ and treated with collagen type IV. The cells were then divided into four groups: the first group was composed of cells without any treatment, the second group was composed of cells infected with control lentivirus vector, the third group was composed of transduced cells, and the forth group was composed of cells that were exposed to $10^{-7} \mathrm{M}$ SP. Every other day after day 2 until day 12 post-treatment, $10 \mu \mathrm{L}$ of CCK-8 (Boster, China) solutions were added to each well, and the samples were incubated for $2 \mathrm{~h}$. The specific absorbance at $450 \mathrm{~nm}$ $\left(\mathrm{A}_{450}\right)$ was determined using a Micro-plate Reader (Thermo Fisher, USA). All of the experiments were repeated independently at least three times, and each measurement was the average of 5 duplicate wells. 


\section{Western blotting}

The total cell lysates of EpSCs that underwent the proliferation and differentiation were obtained by lysing the cells in RIPA buffer (Boster, China) containing $50 \mathrm{mM}$ Tris- $\mathrm{HCl}, 150 \mathrm{mM} \mathrm{NaCl}, 1 \% \mathrm{NP}-40,0.1 \%$ SDS, $0.5 \%$ sodium deoxycholate, $2 \mathrm{mM}$ sodium fluoride, $1 \mathrm{mM}$ EDTA, $1 \mathrm{mM}$ EGTA and a protease inhibitor cocktail. The protein concentration was determined using the bicinchoninic acid protein assay (Beyotime, China). The proteins were separated by SDS-PAGE, transferred to nitrocellulose, blocked with bovine serum albumin and incubated with the following primary antibodies: rat anti- $\beta$-catenin (CST, USA) diluted $1: 1000$, rat anti-p- $\beta$ catenin (CST, USA) diluted 1:1000, rat anti-c-myc (CST, USA) diluted 1:1000, rat anti-Nanog (CST, USA) diluted 1:2000, rat anti-GSK3 $\beta$ (CST, USA) diluted 1:1000, rat anti-p-GSK3 $\beta$ (CST, USA) diluted 1:1000 or rat antiGAPDH (Beijing Biosynthesis Biotechnology, China) diluted 1:1000 that was used as a loading control. The membrane was washed and incubated with the respective secondary antibodies conjugated with peroxidase. Chemiluminescence (Bio-Rad, USA) was used to detect protein.

\section{Real-time quantitative PCR}

Total RNA was extracted using the TRIzol reagent (Invitrogen, USA), according to the manufacturer's protocol. Using a spectrophotometer (Eppendorf, Germany), the RNA concentration and purity were determined by $A_{260}$ and $\mathrm{A}_{260} / \mathrm{A}_{280}$ ratios, respectively. Total RNA was used to synthesize cDNA with a Super-Script II cDNA synthesis kit (Invitrogen Life Technologies, USA). The related genes of the $\mathrm{Wnt} / \beta$-catenin signaling pathway and Nanog were assessed by quantitative real-time PCR using a SYBR-Green Master mix (Fermentas, Vilnius, Lithuania). Glyceraldehyde phosphate dehydrogenase (GAPDH) was selected as an internal control. The primer sequences are: Nanog (accession no. NM_0011 00781) forward, CCGTTGGGCTGACATGAGCGT and reverse, GGCAGGCATCGGCGAGGAAT; $\beta$-catenin (accession no. NM_053357) forward, AGCCCGTTGTACCGCTGGGA and reverse, CGCTGGGATGCCGCCAGATT; c-myc (accession no. NM_012603) forward, CATCATCCAGGACTGTATGTG and reverse, TGGA ATCGGACGAGGTA; GAPDH (accession no. NM_0170 08) forward, TATGACTCTACCCACGGCAAGT and reverse, ATACTCAGCACCAGCATCACC.

\section{Statistical analysis}

All experiments were repeated independently at least three times. The data are presented as the mean \pm standard deviation (SD). The results were analyzed using SPSS 18.0 statistical software. Statistically significant differences were identified using Student's t-test and an analysis of variance (ANOVA). The significance level was set to $\mathrm{P}<0.05$.

\section{Competing interests}

The authors declare that they have no competing interests.

\section{Authors' contributions}

PC and XYS carried out most of the experiments and drafted the manuscript; FX carried out a part of vitro studies; KXY, LQ and YHD assisted in the in vitro studies; DLY, FJG and AMC participated in the design of the studies; WKZ participated in the design of the studies and revising the manuscript; $\mathrm{HH}$ conceived the studies, coordinated the experiments and was involved in the drafting manuscript. All authors read and approved the final manuscript.

\section{Acknowledgements}

This study was supported by the National Natural Science Foundation of China (No. 30872691 and No.81300828).

\section{Author details}

'Department of Orthopedics, Tongji Hospital, Tongji Medical College, Huazhong University of Science and Technology, Wuhan 430030, P.R. China ${ }^{2}$ Biological engineering and regenerative medicine center,Tongji Hospital, Tongji Medical College, Huazhong University of Science and Technology, Wuhan 430030, P.R. China. ${ }^{3}$ Department of Orthopedics, The Third Hospital Affiliated to Guangzhou Medical University, Guangzhou 510150, P.R. China.

Received: 15 July 2014 Accepted: 16 January 2015

Published: 27 January 2015

\section{References}

1. Fordham RP, Jensen KB. Reporting live from the epidermal stem cell compartment! Cell Stem Cell. 2012;11(2):141-2.

2. Watt FM, Jensen KB. Epidermal stem cell diversity and quiescence. EMBO Molecular Medicine. 2009;1 (5):260-7.

3. Chai L, Cao C, Bi S, Dai X, Gan L, Guo R, et al. Small Rho GTPase Rac1 determines human epidermal stem cell fate in vitro. Int J Mol Med. 2010;25(5):723-7.

4. Luo Y, Lim CL, Nichols J, Martinez-Arias A, Wernisch L. Cell signalling regulates dynamics of Nanog distribution in embryonic stem cell populations. J R Soc Interface. 2013;10(78):20120525.

5. MacArthur BD, Sevilla A, Lenz M, Müller F, Schuldt BM, Schuppert AA, et al. Nanog-dependent feedback loops regulate murine embryonic stem cell heterogeneity. Nat Cell Biol. 2012;14(11):1139-47.

6. Han J, Mistriotis P, Lei P, Wang D, Liu S, Andreadis ST. Nanog reverses the effects of organismal aging on mesenchymal stem cell proliferation and myogenic differentiation potential. Stem Cells. 2012;30(12):2746-59.

7. Chambers I, Colby D, Robertson M, Nichols J, Lee S, Tweedie S, et al. Functional expression cloning of Nanog, a pluripotency sustaining factor in embryonic stem cells. Cell. 2003;113(5):643-55.

8. Davidson KC, Adams AM, Goodson JM, MCDonald CE, Potter JC, Berndt JD, et al. Wnt/ $\beta$-catenin signaling promotes differentiation, not self-renewal, of human embryonic stem cells and is repressed by Oct4. Proc Natl Acad Sci. 2012;109(12):4485-90.

9. Sokol SY. Maintaining embryonic stem cell pluripotency with Wnt signaling. Development. 2011;138(20):4341-50.

10. Watt FM, Collins CA. Role of beta-catenin in epidermal stem cell expansion, lineage selection, and cancer. Cold Spring Harb Symp Quant Biol. 2008;73:503-12.

11. Gannon HS, Donehower LA, Lyle S, Jones SN. Mdm2-p53 signaling regulates epidermal stem cell senescence and premature aging phenotypes in mouse skin. Dev Biol. 2011;353(1):1-9.

12. Luis NM, Morey L, Mejetta S, Pascual G, Janich P, Kuebler B, et al. Regulation of human epidermal stem cell proliferation and senescence requires polycomb- dependent and -independent functions of Cbx4. Cell Stem Cell. 2011;9(3):233-46.

13. Berta MA, Baker CM, Cottle DL, Watt FM. Dose and context dependent effects of Myc on epidermal stem cell proliferation and differentiation. EMBO Molecular Medicine. 2010;2(1):16-25.

14. Flores I, Blasco MA. A p53-dependent response limits epidermal stem cell functionality and organismal size in mice with short telomeres. PLoS One. 2009;4(3):e4934. 
15. Mei G, Xia L, Zhou J, Zhang Y, Tuo Y, Fu S, et al. Neuropeptide SP activates the WNT signal transduction pathway and enhances the proliferation of bone marrow stromal stem cells. Cell Biol Int. 2013;37(11):1225-32.

16. Liu Y, Zhou H, Gao F. Isolation and identification of stem cells from adult cashmere goat skin. Int J Dermatol. 2008;47(6):551-6.

17. Li A, Simmons PJ, Kaur P. Identification and isolation of candidate human keratinocyte stem cells based on cell surface phenotype. Proc Natl Acad Sci U S A. 1998;95(7):3902-7.

18. Baer PC, Brzoska M, Geiger H. Epithelial differentiation of human adiposederived stem cells. Methods Mol Biol. 2011;702:289-98.

19. Ruetze M, Dunckelmann K, Schade A, Reuschlein K, Mielke H, Weise JM, et al. Damage at the root of cell renewal-UV sensitivity of human epidermal stem cells. J Dermatol Sci. 2011;64(1):16-22.

20. Aberdam D. Epidermal stem cell fate: what can we learn from embryonic stem cells? Cell Tissue Res. 2008;331(1):103-7.

21. Bourguignon LYW, Wong G, Earle C, Chen L. Hyaluronan-CD44v3 interaction with Oct4-Sox2-nanog promotes miR-302 expression leading to self-renewal, clonal formation, and cisplatin resistance in cancer stem cells from head and neck squamous cell carcinoma. J Biol Chem. 2012;287(39):32800-24.

22. Sieber-Blum M. Epidermal stem cell dynamics. Stem cell research \& therapy. 2011;2(3):29.

23. Anton R, Kestler HA, Kühl M. $\beta$-Catenin signaling contributes to stemness and regulates early differentiation in murine embryonic stem cells. Febs Lett. 2007:581(27):5247-54.

24. Redvers RP, Li A, Kaur P. Side population in adult murine epidermis exhibits phenotypic and functional characteristics of keratinocyte stem cells. Proc Natl Acad Sci U S A. 2006;103(35):13168-73.

25. Mitsui K, Tokuzawa Y, Itoh H, Segawa K, Murakami M, Takahashi K, et al. The homeoprotein Nanog is required for maintenance of pluripotency in mouse epiblast and ES cells. Cell. 2003;113(5):631-42.

26. Tay Y, Zhang J, Thomson AM, Lim B, Rigoutsos I. MicroRNAs to Nanog, Oct4 and Sox2 coding regions modulate embryonic stem cell differentiation. Nature. 2008;455(7216):1124-8.

27. Xu X, Wang HY, Zhang Y, Liu Y, Li YQ, Tao K, et al. Adipose-derived stem cells cooperate with fractional carbon dioxide laser in antagonizing photoaging: a potential role of Wnt and beta-catenin signaling. Cell Biosci. 2014;4:24.

28. Castilho RM, Squarize CH, Chodosh LA, Williams BO, Gutkind JS. mTOR mediates Wnt-induced epidermal stem cell exhaustion and aging. Cell Stem Cell. 2009;5(3):279-89.

29. Miki T, Yasuda S, Kahn M. Wnt/ $\beta$-catenin signaling in embryonic stem cell self-renewal and somatic cell reprogramming. Stem Cell Rev Rep. 2011;7(4):836-46.

30. Sato N, Meijer L, Skaltsounis L, Greengard P, Brivanlou AH. Maintenance of pluripotency in human and mouse embryonic stem cells through activation of Wnt signaling by a pharmacological GSK-3-specific inhibitor. Nat Med. 2003;10(1):55-63.

31. Haegele L, Ingold B, Naumann H, Tabatabai G, Ledermann B, Brandner S. Wnt signalling inhibits neural differentiation of embryonic stem cells by controlling bone morphogenetic protein expression. Mol Cell Neurosci. 2003;24(3):696-708.

32. Yin D, Tian L, Ye Y, Li K, Wang J, Cheng P, et al. Nanog and beta-catenin: a new convergence point in EpSC proliferation and differentiation. Int J Mol Med. 2012;29(4):587-92.

33. Ghadially R. 25 years of epidermal stem cell research. The Journal of investigative dermatology. 2012;132(3 Pt 2):797.

34. Doles J, Storer M, Cozzuto L, Roma G, Keyes WM. Age-associated inflammation inhibits epidermal stem cell function. Gene Dev. 2012;26(19):2144-53.

35. Li J, Miao C, Guo W, Jia L, Zhou J, Ma B, et al. Enrichment of putative human epidermal stem cells based on cell size and collagen type IV adhesiveness. Cell Res. 2008;18(3):360-71.

36. Brzoska M, Geiger H, Gauer S, Baer P. Epithelial differentiation of human adipose tissue-derived adult stem cells. Biochem Bioph Res Co. 2005;330(1):142-50.

37. Wray J, Hartmann C. WNTing embryonic stem cells. Trends Cell Biol. 2012;22(3):159-68.

doi:10.1186/2045-3701-5-5

Cite this article as: Cheng et al:: Nanog down-regulates the Wnt signaling pathway via $\beta$-catenin phosphorylation during epidermal stem cell proliferation and differentiation. Cell \& Bioscience 2015 5:5.

\section{Submit your next manuscript to BioMed Central and take full advantage of:}

- Convenient online submission

- Thorough peer review

- No space constraints or color figure charges

- Immediate publication on acceptance

- Inclusion in PubMed, CAS, Scopus and Google Scholar

- Research which is freely available for redistribution

Submit your manuscript at www.biomedcentral.com/submit 